\title{
Loteamentos \\ irregulares em \\ área de risco no \\ município de \\ São José dos \\ Campos/SP, Brasil
}

\author{
Maria de Fátima Moura Gomes, \\ Mario Valerio Filho, \\ Rodolfo Moreda Mendes, \\ Lidiane Maria Maciel*
}

\begin{abstract}
Resumo São José dos Campos, no estado de São Paulo, possui inúmeros loteamentos irregulares em áreas de risco, especialmente, em Área de Preservação Ambiental e Área de Topo de Morro. O objetivo do artigo é discutir a questão da vulnerabilidade socioambiental na cidade supracitada, destaca-se no estudo o bairro de Santa Helena, como hipótese considera-se que as políticas habitacionais fizeram com que a população mais empobrecida ocupasse as áreas periféricas desprovidas de estrutura urbana. A metodologia é descritiva e como resultados e conclusões se observa que as ações municipais para mitigar os riscos e regularizar os bairros ainda são insuficientes.
\end{abstract}

Palavras-chave: urbanização, áreas de risco, loteamentos irregulares.

\section{Barrio irregulares en zona de riesgo en São José dos Campos, São Paulo, Brasil}

\begin{abstract}
Resumen San José dos Campos, en Sao Paulo, cuenta con numerosos barrio irregulares en zonas de vulnerabilidad socioambiental, especialmente en el área de preservación ambiental y zona de Morro. El objetivo es discutir el riesgo en la ciudad. El barrio de Santa Helena se destaca como un caso de estudio, como hipótesis se considera que las políticas de vivienda hicieron que la población más empobrecida ocupara zonas periféricas carentes de estructura urbana. La metodología es descriptiva y como resultados y conclusiones se observa que las acciones municipales para mitigar los riesgos y regularizar los barrios siguen siendo insuficientes.
\end{abstract}

Palabras clave: urbanización, áreas de riesgo, asignaciones irregulares.
Irregular terrains in risk area in the municipality of São José dos Campos, São Paulo, Brazil

\begin{abstract}
São José dos Campos, in the São Paulo, has numerous irregular areas in socio-environmental vulnerability, especially in the environmental preservation area and the "Topo de Morro" Area. The objective is to discuss the issue of risk in the city, as a case study we take the neighborhood of Santa Helena, as a hypothesis it is considered that housing public policies have caused the impoverished population to occupy peripheral areas without an urban structure. The methodology is descriptive and as results and conclusions it is observed that the municipal actions to mitigate the risks and regularize the neighborhoods are still insufficient.
\end{abstract}

Keywords: urbanization, risk areas, irregular allotments. 
* Maria de Fátima Moura Gomes é Arquiteta e Urbanista, Mestre em Planejamento Urbano e Regional da Universidade do Vale do Paraíba, ORCID <https://orcid. org/0000-0003-4592-8761> Mario Valerio Filho é Engenheiro Agrônomo, Professor em Planejamento Urbano e Regional da Universidade do Vale do Paraíba, ORCID <https://orcid.org/00000001-9268-8970>. Rodolfo Moreda Mendes é Engenheiro Civil, Professor em Planejamento Urbano e Regional da Universidade do Vale do Paraíba, ORCID <https://orcid.org/0000-0003-18333084>. Lidiane Maria Maciel é Cientista Social, Professora em Planejamento Urbano e Regional da Universidade do Vale do Paraíba, ORCID <https://orcid. org/0000-0002-5029-7645>.
No - Brasil a incidência de desastres urbanos que envolvem vítimas assume cada vez mais visibilidade no debate público. A ocupação irregular do solo nas cidades, não é necessariamente a causa dos mesmos, no entanto, este argumento é o primeiro a ser listado na busca de explicações imediatas para as eventuais tragédias. Recortando essa problemática nacional, o objetivo deste artigo é discutir a vulnerabilidade em loteamentos irregulares, em São José dos Campos, São Paulo.

Observa-se que por mais que o município apresentasse nas últimas décadas índices significativos de qualidade de vida, como do Índice de Desenvolvimento Humano (IDHM) - 0,807, em 2010), ele ainda possui ocupações irregulares, cujas causas de seu aparecimento estão na gestão política econômica do território (HARVEY, 2005). No atual momento do desenvolvimento capitalista a problemática da irregularidade fundiária se liga a lógica da produção do espaço. Essa lógica é percebida especialmente nas legislações que orientam o ordenamento territorial.

Nas décadas de 60 e 80 a urbanização foi acelerada sendo fruto das migrações internas. Este processo ocasionou grandes implicações na produção das aglomerações urbanas e formação de loteamentos irregulares. No caso de São José dos Campos, Gouveia (2003) mostra que desde a década de 1970 houve a expansão dos loteamentos "clandestinos" (irregulares) de forma significativa tanto na zona norte, leste e sul que adensaram áreas empobrecidas da cidade.

O caso do loteamento Santa Helena, por exemplo, evidencia essa problemática, localizado em uma região marcada por declividades acentuadas, sendo que parte da área ocupada irregularmente pelas edificações, estão assentadas na várzea do córrego marginal ao loteamento.

Os loteamentos irregulares, possuem uma população socioeconomicamente desfavorecida que muitas vezes se encontra à deriva das políticas públicas habitacionais, apresentando um grau de vulnerabilidade socioambiental (MARANDOLA JR.; HOGAN, 2006). Que segundo Cartier et al. (2009)

pode ser conceituada como uma coexistência ou sobreposição espacial entre grupos populacionais pobres, discriminados e com alta privação (vulnerabilidade social), que vivem ou circulam em áreas de risco ou de degradação ambiental (vulnerabilidade ambiental). (CARTIER et al., 2009, p. 2696)

De fato, há um contexto de injustiça ambiental (ACSELRAD, 2010, p. 109) em que "os mais ricos conseguiriam escapar aos riscos e os mais pobres circulariam no interior de um circuito de risco". Dessa forma, é importante frisar que os moradores em áreas de risco estão em suscetíveis à desastre. Considerados como uma grave perturbação do funcionamento da comunidade que envolve perdas humanas, materiais, econômicas ou ambientais de grande extensão (TOMINAGA, 2009), em que seus princípios estão, 
1 IPPLAN - Relatório Completo do Plano Municipal de Redução de Risco (PMRR) FASE I e FASE II. Disponível em: <https://www. sjc.sp.gov.br/media/45004/ pmrr_final_i_e_ii.pdf $>$. Acesso em 26/09/2019 e 08/06/2020. para além das explicações imediatas, incluído as religiosas, eles então refletem nexos históricos e sociais (VALÊNCIO, 2010).

Os desastres no Brasil, particularmente, no estado de São Paulo estão associados principalmente aos casos de escorregamentos e inundações. A urbanização e a consequente ocupação de áreas com grandes restrições a edificações estão na origem do problema. O crescimento da cidade por meio das ocupações desordenadas e irregulares nas periferias, que ocorre em desrespeito às leis de uso e ocupação do solo e as leis ambientais, colocam a população em situação de risco. Dessa forma a natureza dos desastres pode ser olhada via processos ligados a vulnerabilidade sociais. "No caso brasileiro, um contexto socio-histórico das mais absolutas e estruturais desigualdades que se refletem territorialmente é uma das variáveis de análise que são consideradas" (VALÊNCIO, 2010, p. 73). Dessa maneira, a questão fundiária urbana reflete as condições da produção capitalista do espaço, a ocupação de áreas de risco é fruto dessa ordem.

Orientando-se para o caso empírico, sabe-se que São José dos Campos dispõe de um Plano de Gestão de riscos como parâmetro para o desenvolvimento urbano e deste modo propõe ações para prevenção de risco, o documento segue as diretrizes propostas pelo antigo Ministério das Cidades, as medidas devem atender às seguintes questões 1) Identificação e análise dos riscos; 2) Prevenção e redução de acidentes; 3) Planejamento para situações de emergência e 4) Informação pública e capacitação, especialmente para os agentes públicos e moradores dos assentamentos sujeitos a riscos, contudo o mesmo não acontece em outros municípios da região do Vale do Paraíba. ${ }^{1}$

No debate maior, a lei federal 12.608/2012 dispõe sobre Sistema Nacional de Proteção e Defesa Civil - SINPDEC e o Conselho Nacional de Proteção de Defesa Civil - CONPDEC. Em seu Cap.II, Art. $3^{\circ}$ estabelece que a Política Nacional de Proteção e Defesa Civil (PNPDEC) abrange as ações de prevenção, mitigação, preparação, resposta e recuperação voltadas à proteção e defesa civil e que deverá integrar-se às políticas de ordenamento territorial, desenvolvimento urbano, infraestrutura, e demais políticas visando a promoção do desenvolvimento sustentável.

A PNPDEC atua em todo o município integrada às políticas do município, particularmente as ações referentes à ocupação dos loteamentos irregulares que se fazem em regiões reconhecidas como de risco.

A incidência de loteamentos irregulares é maior em áreas identificadas como Área de Risco. A Lei 12.608/2012 em seu art. $8^{\circ}$ define a competência dos municípios na execução e coordenação das ações do PNPDEC no âmbito local; na incorporação de ações de planejamento municipal; na identificação e mapeamento das áreas de risco de desastres, na fiscalização das áreas de risco e em impedir novas ocupações nestas áreas. Dessa forma, caberá a Defesa Civil Municipal atuar junto às ocupações irregulares que incidam riscos, no mapeamento e identificação de áreas de possíveis desastres.

Ainda a PNPDEC, em seu art. 23 determina que: "É vedada a concessão de licença ou alvará de construção em áreas de risco indicadas como não edificáveis no Plano Diretor ou legislação nele derivada". Contudo, a dinâmica urbana, muitas vezes, 
desvinculada da política habitacional dos municípios, somada aos frágeis mecanismos de controle disponível, são responsáveis pelo surgimento de ocupações irregulares e em áreas de risco.

O caso do bairro Santa Helena é exemplar desse processo, possuí áreas ocupadas que não são passíveis de regularização dado ao risco eminente de deslizamentos, no entanto, dada a própria dinâmica urbana, o loteamento cresce de maneira espontânea ou sem critérios diretamente estabelecidos. Verifica-se que abertura de novos lotes nessas áreas é fruto da falta de alternativa a população de baixa renda que lá ocupa. A questão fundiária urbana em São José dos Campos, como em outras cidades brasileiras, se apresenta por meio da expansão da periferia longínqua do centro do município, muitas em áreas de risco. Compreende-se ainda que políticas públicas como o Programa Minha Casa Minha Vida (PMCMV) que minimizariam os efeitos do processo desigual de acesso à terra urbana, acabaram por promover a financeirização da questão da moradia e segregação socioespacial, conforme demonstram Alvarenga e Reschilian (2018).

A partir dessas considerações o artigo se organiza em quatro momentos principais à saber: no primeiro dedica-se a abordar a problemática inicial da urbanização no Brasil, em seguida parte-se para a exposição de elementos do desenvolvimento histórico e social de São José dos Campos, em terceiro discute-se a ocupação e ordenamento do solo, com destaque ao o caso dos loteamentos, para por fim, ilustrarmos o debate por meio do estudo de caso do bairro de Santa Helena. A metodologia utilizada se apoia em pesquisas de campo realizadas pelos autores entre os anos de 2016 e 2019 e na análise de documentos institucionais/legislações que versam sobre o tema.

\section{Problemáticas iniciais da urbanização}

No Brasil, a partir do ciclo do café, ainda no final do século XIX, o redirecionamento da esfera produtiva para o Sudeste e a industrialização favoreceu a formação de grandes centros, marcadamente adensado (SINGER,1973). Em 1950 já se destacavam as cidades de São Paulo e Rio de Janeiro como lócus da pequena, média e grande manufatura. Assim, a concentração industrial, sudeste centrada, colaborou para redistribuição da população no território e a partir de 1940 até 1970, especialmente, a cidade de São Paulo passou a receber levas significativas de migrantes interno que junto aos imigrantes, das políticas imigratórias brasileiras do final do século XIX, compuseram a força de trabalho da indústria paulista. (CANO, 1990; BAENINGER, 2010).

Em São Paulo medidas urbanísticas e higienistas foram tomadas, no sentido de ordenar o crescimento populacional e a ocupação urbana. As melhorias urbanas das regiões centrais em favorecimento de produtores agrícolas que lá se instalavam, determinaram a segregação e exclusão da classe mais pobre, que lá habitavam (REIS, 2006). Tais melhorias ocorreram no período sanitarista e como políticas públicas visavam a difusão e massificação de valores culturais cujos propósitos eram morais que se empregavam sobre a limpeza ordem e a organização dos lugares de morar, trabalhar e uso público (GUNN, 2010). Essas intervenções visavam encontrar os meios práticos para executar a profilaxia de áreas públicas, contra a peste que infectavam as cidades no séc. XIX, e como medidas urbanísticas procuravam higienizar as áreas centrais, que buscavam justificar a busca pela extinção das áreas denominadas cortiços e a expulsão da 
população de baixa renda das regiões. A justificativa era pelo sentido moral e social da época, como relata Rolnik (1997)

A expulsão da população mais pobre das regiões centrais da cidade e a busca de refúgio nas áreas periféricas da cidade deram origem aos cortiços e as favelas, como alternativa de moradia à população de baixa renda, renegadas a um território desprovido de recursos urbanos, sendo ao longo dos anos, obrigados a se afastarem, mais e mais dos centros. Alfonsín (2000, p. 197) afirma que: "As favelas, que de início formavam um anel ao redor da cidade, passaram a estar presentes em todo o tecido urbano, pontuando a malha formal com "manchas" de ocupação irregular".

O crescimento industrial e o desenvolvimento do urbanismo nas áreas centrais necessitavam de obras de favorecimento no sentido de abrigar a nova classe em ascensão, favorecendo a transformação destes espaços, dotando-as de infraestrutura. Os terrenos urbanos foram valorizados e influenciaram diretamente a segregação social e o afastamento da população operária e mais pobre empurradas para as periferias (KOWARICK, 1979, VILLAÇA, 2001).

As melhorias urbanas (abertura de ruas, obras de infraestrutura, residências mais bem elaboradas, melhorias no sistema viário etc.), e um mercado de trabalho que demandava muita mão de obra fortaleceu os fluxos migratórios internos, atraídos pelas promessas de melhora de vida (DURHAM, 1983; MACIEL, 2013). No entanto, ao mesmo tempo, a implementação destas melhorias urbanas, não era constatada na periferia.

O contingente populacional, mão de obra necessária a indústria, comércio e serviços, não dispunha de meios para obtenção de moradia, não dispunha de meios para se estabelecer legalmente, restando-lhes somente se dirigirem às periferias, ampliando a ocupação em áreas distantes dos centros, local onde a terra possuía um valor mais acessível (KOWARICK, 1979), contudo tais áreas eram quase sempre, desprovidas de melhorias urbanas, geralmente em áreas de topo de morro (APP), várzeas, ao longo dos córregos e rios. Os moradores ao edificar suas casas em encostas, longe das preocupações do poder público, passaram a lidar com o risco iminente de deslizamentos de terra.

É necessário entender que o parcelamento irregular do solo causa transtornos onde são empreendidos, e afetam a cidade como um todo, evidentemente, os moradores são os que estão sob maior risco. Esses assentamentos promovem:

a desarticulação do sistema viário, dificultando o acesso de ônibus, ambulâncias, viaturas policiais e caminhões de coleta de lixo; a formação de bairros sujeitos a erosão e alagamentos, o assoreamento de rios, lagos e mares; a ausência de espaços públicos para implantação de equipamentos de saúde, educação, lazer e segurança; o comprometimento de mananciais de abastecimento de água e do lençol freático; ligações clandestinas de energia elétrica, que resultam em acidentes e incêndios; e a expansão horizontal excessiva da malha urbana, ocasionando elevado ônus para o orçamento público. (LEITE, 2014, p.155)

Diante das situações decorrentes da ocupação irregular nas cidades, a regularização fundiária surge como uma solução para que possam ser coibidas as transgressões ao meio ambiente, a partir do ordenamento do solo urbano e das medidas necessárias 
a reparação dos danos infringidos ao meio ambiente e atua como um modo eficaz no controle aos danos causados e as situações de risco pelos quais a população se envolve pelo fato da ausência de controle e políticas urbanas nestas regiões ocupadas informalmente.

Segundo Ferraz (2014) a precariedade das ocupações em áreas de risco é sem sombra de dúvida a mais perversa, considerando que a população fica exposta a desastres, tais como: deslizamentos e inundações, a qualquer momento. A conversão ou progressão destas áreas para o status de direito de propriedade (registrar o imóvel no Cartório de Registro), é inviável, devido às diversas circunstâncias fáticas adversas que acabam por inviabilizar o reconhecimento desta posse pelo poder público, pelo fato de que em áreas de risco não há possibilidade de regularização fundiária, a não ser pelo fato do município ter o "poder-dever" de remover os ocupantes destas áreas para áreas mais seguras. Podendo algumas vezes o risco ser atenuado por meio de obras de engenharia, contudo, somente após a remoção dos moradores da área de risco seriam permitidos os procedimentos jurídicos necessários para a regularização da área.

No entanto, é possível afirmar que a questão fundiária no Brasil, especialmente a urbana, torna-se um elemento explicativo importante para o entendimento das contradições emergentes do processo de ocupação do solo periférico (MARICATO, 2000), e ainda, como explica Fernandes (2002):

Os assentamentos informais (...) resultam não somente do padrão excludente dos processos de desenvolvimento, planejamento e gestão das áreas urbanas, mas também da natureza da ordem jurídica em vigor. Ao longo do processo de urbanização intensiva, mercados de terras especulativos, sistemas políticos clientelistas e regimes jurídicos elitistas não têm oferecido condições suficientes, adequadas e acessiveis de acesso à terra urbana e à moradia, para os grupos sociais mais pobres, assim provocando a ocupação irregular e inadequada do meio ambiente urbano.

Dessa forma compreende-se que há uma historicidade no processo de irregularidade que acompanha a formação das cidades no século XX, que por meio da urbanização pautada pela indústria e da capitalização do solo urbano (lógica da especulação imobiliária) juntamente um sistema jurídico elitista colaborou para as condições urbanas tais como se apresentam em diversas cidades brasileiras.

\section{São José dos Campos: desenvolvimento econômico e urbanização}

São José dos Campos, localizado no Estado de São Paulo (Figura 1), mais precisamente na Região Metropolitana do Vale do Paraíba e Litoral Norte (RMVPLN), é reconhecido como polo industrial da região metropolitana, com uma área territorial de 1.099,60 $\mathrm{km}^{2}$, urbana: $353,90 \mathrm{~km}^{2}$ e rural: $745,70 \mathrm{~km}^{2}$. Na área urbana a altitude média varia entre 550 a 690 metros acima do nível do mar.

A partir da década de 1960, questões relacionadas a irregularidade fundiária, formação de periferias, e as consequências de uma urbanização acelerada também se apresentaram nas cidades paulistas que se beneficiaram da chamada "desconcentração industrial" (NEGRI,1995). 
Figura 1: Localização do Município de São José dos Campos. Fonte: Adaptado da Base de Dados-IBGE (2015).

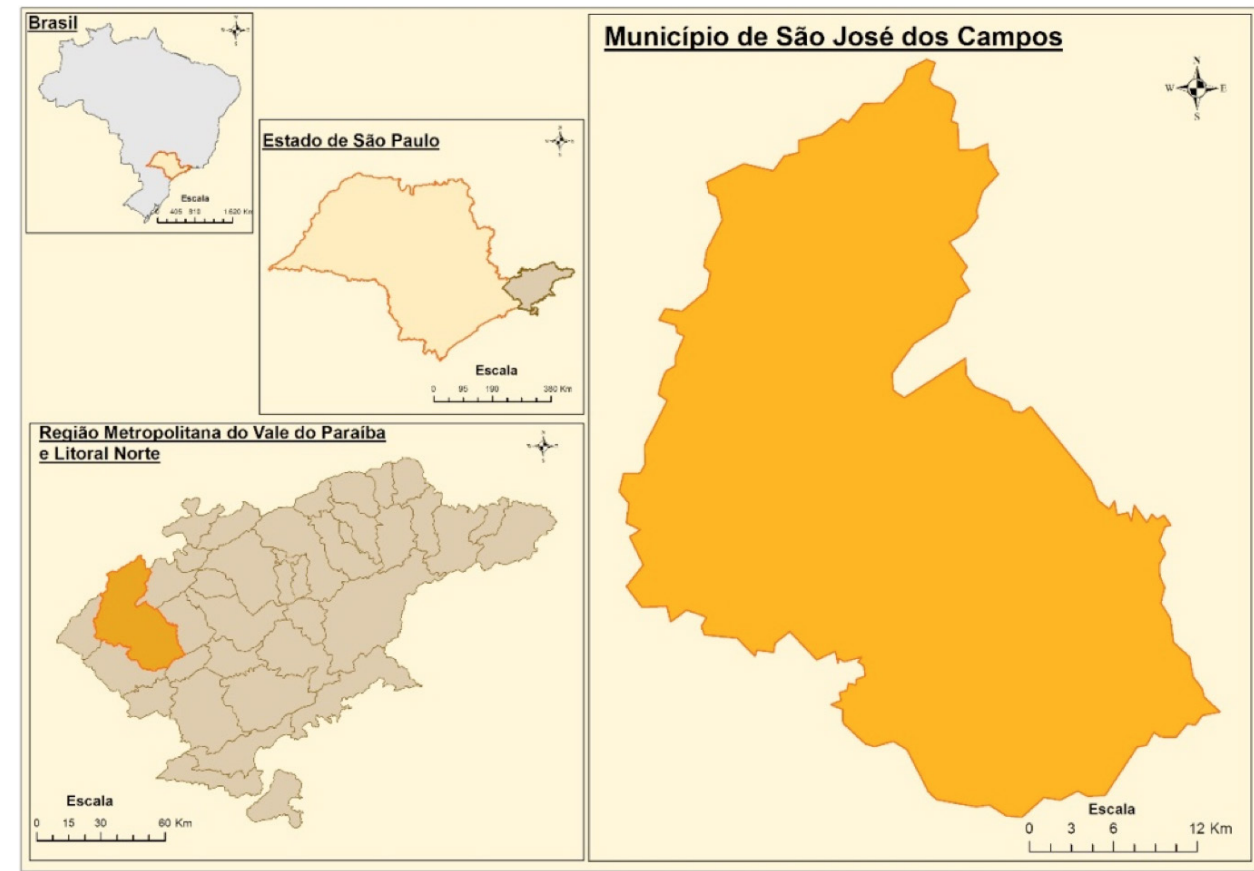

Nota-se neste período de 1970, um grande desenvolvimento no interior paulista, que se concentrou nas regiões de Campinas, Baixada Santista e Vale do Paraíba. Foi registrado nestas aglomerações o maior crescimento industrial no interior paulista, em que a partir do milagre econômico, a cidade de São José dos Campos se tornou o terceiro parque industrial paulista, com a implantação de um centro de desenvolvimento de tecnologia militar e aeroespacial (CTA/ITA) e grandes empresas, entre elas a estatal Embraer. Destaca-se, ainda desse ambiente empresarial a Johnson \& Johnson (1953); Ericsson (1954); General Motors (1959); Alpargatas (1960); Amplimatic e Matarazzo (1964); Avibrás (1965); Embraer (1969); National (1970); Kodak (1972); Phillips, Hitachi e Engesa (1973); Monsanto (1975), destaca-se a Refinaria Henrique Lage, em 1980.

O crescimento acelerado foi consequência da reestruturação da rede urbana regional que incluía novas diretrizes criadas pelo II Plano Nacional de Desenvolvimento (II PND).

Dentre suas diretrizes, destacam-se: a coordenação de investimentos e a regulamentação do uso do solo; a contenção do crescimento metropolitano aliada à descentralização produtiva para centros de médio porte; planejar e disciplinar a urbanização da orla marítima, conciliando turismo lazer e preservação ambiental (São Paulo, 1978, p. 2). (GOMES, RESCHILIAN, UEHARA, 2018; p.159).

No caso de São José dos Campos, o processo de industrialização e a rápida expansão de seu perímetro favoreceu a especulação imobiliária e estimulou o surgimento de loteamentos irregulares, esse problema começou a ser relatado já na primeira proposta de Plano Diretor da cidade ainda em 1965, conforme mostra o trabalho de Gouveia (2003) 
Tabela 1: Evolução da população de São José dos Campos (19402020). Fonte: Censos Demográficos - IBGE e Fundação SEADE (2020).
Na Tabela 1 é possível constatar que em 1950, em São José dos Campos, a população urbana superou a rural. O crescimento populacional urbano de 1960 a 1970 foi de $132,91 \%$; de 1970 a 1980 foi de $109,01 \%$; de 1980 a 1991 foi de 53,67\%; de 1991 a 2000 foi de $25,19 \%$; de 2000 a 2010 foi de $15,45 \%$ e de 2010 a 2020 foi de $10,73 \%$. Constatou-se que da década de 60 até a década de 80 houve um crescimento vertiginoso revelando a influência na ocupação do solo e do crescimento dos loteamentos irregulares no município.

O crescimento foi motivado por fluxos migratórios que atingiram a região até os anos recentes. O Censo Demográfico de 1980 registrou uma população total 287.513 habitantes, quarenta anos depois em 2020, a população era de 710.654 mil habitantes. O estudo de Baeninger et. al (2010) e Cunha, Silva e Becceneri (2019) apontava que São José dos Campos permaneceu com os maiores saldos migratórios da Região desde a década de 1980.

Considerando ainda os dados do último Censo Demográfico (2010) verifica-se que em 2010, 45\% da população residente em São José dos Campos, não era nativa. O saldo migratório em 2000 era de 3.474 e em 2010 de 2.797, o que significa que nas primeiras décadas a participação dos migrantes no crescimento populacional caiu em relação a década de 1990 (5.407), no entanto, os migrantes ainda são peças importante no desenvolvimento da cidade. Destaca-se também, analisando os Microdados do Censo Demográfico (2010), o aumento dos deslocamentos pendulares entre as cidades de São José dos Campos e Jacareí, o que pode indicar fortalecimento da integração entre as cidades da Região Metropolitana do Vale do Paraíba e Litoral Norte.

Deste modo, nas últimas décadas, em São José dos Campos, a demanda por espaço aumentava à medida que a população crescia e buscava locais próximos aos locais de trabalho para morar. Neste sentido, houve a elevação de valores de determinados bairros, devido a fatores como: localização, fluidez viária, infraestrutura, situações de lazer, comércio local etc. A oferta de terra se baseava na compra ou no aluguel de terrenos com ou sem construções. Uma vez que as áreas centrais se tornavam caras, foi se formando uma faixa ao redor desta, aqui reconhecida como periferia.

Notadamente, o aumento das vias de acessibilidade, tais como a Rodovia Presidente Eurico Gaspar Dutra (BR-116) inaugurada ainda 1951 foi essencial ao desenvolvimento de

\begin{tabular}{cccc}
\hline \multicolumn{4}{c}{ População } \\
\hline Ano & Total & Urbana & Rural \\
1940 & 36.279 & 14.474 & 21.805 \\
1950 & 44.804 & 26.600 & 18.204 \\
1960 & 77.533 & 56.882 & 20.651 \\
1970 & 148.332 & 132.482 & 15.850 \\
1980 & 287.513 & 276.901 & 10.855 \\
1991 & 442.370 & 425.515 & 16.855 \\
2000 & 539.313 & 532.717 & 6.596 \\
2010 & 629.921 & 615.022 & 14.899 \\
2020 & 710.654 & 696.197 & 14.457 \\
\hline
\end{tabular}


São José dos Campos. O desenvolvimento do setor industrial e crescimento populacional ao longo da rodovia se desenvolveu com grande velocidade e formou o um complexo setor produtivo que incluía também as cidades de Guarulhos e Taubaté, cidades que se tornaram polos de crescimento para a região (REIS, 2006). Ainda, segundo Schiffer (2010), o fato de as indústrias saírem da capital paulista para outros estados não se caracterizou em fortalecimento destes como centros industriais autônomos.

Nesse âmbito, São José dos Campos está incluída nas discussões no século XXI que apontam para a formação de uma chamada macrometrópole paulista que inclui as regiões metropolitanas de São Paulo, Campinas, Baixada Santista, Vale do Paraíba e Litoral Norte. (GOMES, RESCHILIAN, UEHARA, 2018).

Por último ressalta-se que o Plano Macro-Eixo Rio-São Paulo, ainda em 1978. Este instrumento foi decisivo para conformação do município de São José dos Campos (GOMES, RECHILLIAN, UEHARA, 2018). O Plano, conforme esclarece Tavares (2018), "propôs uma estratégia de desenvolvimento da região ao redor da rodovia Dutra entre São Paulo e Rio de Janeiro a partir do disciplinamento do seu desenvolvimento industrial e do uso e da ocupação do solo" (TAVARES, 2018, p.348). A realização de uma política regionalizada pareceria ser o caminho a ser seguido.

Dessa forma inspirado nesse movimento, em 1992, concluía-se o Macrozoneamento da Região do Vale do Paraíba e Litoral Norte, cujo objetivo era fazer um planejamento regional e tratava também das questões ambientais demarcadas nas macrozonas urbanas e nas áreas a serem protegidas ambientalmente. Buscava-se com a criação do Macrozoneamento da Região do Vale do Paraíba e Litoral Norte, elaborar noções de desenvolvimento sustentável para a região. (KURKDJIAN et al. 1992).

\section{Ocupação e ordenamento do solo: o caso dos loteamentos e a conduta da regularização fundiária em São José dos Campos}

2 Para aprofundamento da questão história dos loteamentos irregulares em São José dos Campos ver o trabalho de Gouvêia (2003), a autora mostra por meio de um mapeamento qualificado o adensamento e expansão dos mesmos entre os anos de 1988 a 1997.
Um marco demasiadamente significativo para a discussão dos loteamentos irregulares em São José dos Campos se constitui em 1994 quando o poder público instituiu a Lei Complementar n. ${ }^{\circ}$ 114/94, de 22 de dezembro de 1994 que dispõe sobre a criação de Zonas Especiais de Interesse Social (ZEIS). Esta lei classificou deste modo uma série de loteamentos irregulares nesse município ${ }^{2}$, o que chama atenção é que esses loteamentos se apresentam em áreas de risco.

A partir desse momento foi estabelecido estudos na gestão municipal para o processo de delimitação física das ZEIS, utilizando-se imagens de satélite, fotos aéreas e levantamentos topográficos. Em 1997, a LC 165/95 que dispõe sobre a ordenação do território mediante controle do parcelamento, do uso e da ocupação do solo no município, permitiu a inclusão de vários núcleos urbanos nesta categoria, essa lei revogada pela LC 428/2010.

No entanto, em 2006 com a elaboração do PDDI - LC 306/2006 destaca-se ZEIS como instrumento de Política Urbana destinada a projetos à população de baixa renda, e devem ser delimitadas na revisão da legislação do parcelamento, uso e ocupação do solo, sujeitas às diretrizes dos órgãos competentes pela regularização fundiária e urbanística. Na busca pelo controle das construções irregulares, em 2008 o município 
Figura 2: Macrozoneamento Territorial de São José dos Campos -ZEIS. Fonte: Adaptado - Cidade Viva (2011). instituiu a Lei complementar 383/2008, que alterou a Lei 267/2003 - Código de Obras do Município - e autorizou a construção de residências unifamiliares nos loteamentos em processo de regularização fundiária e classificados como ZEIS, cujo objetivo foi que os moradores de áreas irregulares tivessem orientação técnica na construção de casas com segurança na edificação e proteção ambiental. Nesta ocasião foi firmado um convênio entre a Associação de engenheiros e Arquitetos de São José dos Campos, para atender a demanda de Planta Popular, também em áreas irregulares.

A Lei 11.977/2009 introduziu recursos e competências para disciplinar os procedimentos para a regularização fundiária, com instrumentos legais que agilizaram o processo de regularização dos loteamentos. A regularização jurídica promoveria a integração na estrutura urbana da cidade. No entanto, esclarece-se que por mais que haja esforço reflexivos em compreender irregularidade por meio do processo jurídico de ordenamento territorial, a produção da cidade de São José dos Campos vai de encontro com lógicas capitalista de ocupação do espaço. A lei é um produto do embate sobretudo econômico.

Conforme Fernandes (2007) as legislação urbanística municipais possuem uma orientação elitista "baseada em critérios técnicos irrealistas e sem considerar os impactos socioeconômicos das normas urbanísticas" (p. 20). Nesse contexto, a segregação socioespacial é evidente. No caso de São José dos Campos, as ZEIS fazem parte da lógica da exclusão. A Figura 2 ilustra a distribuição espacial das ZEIS no município em 2010.

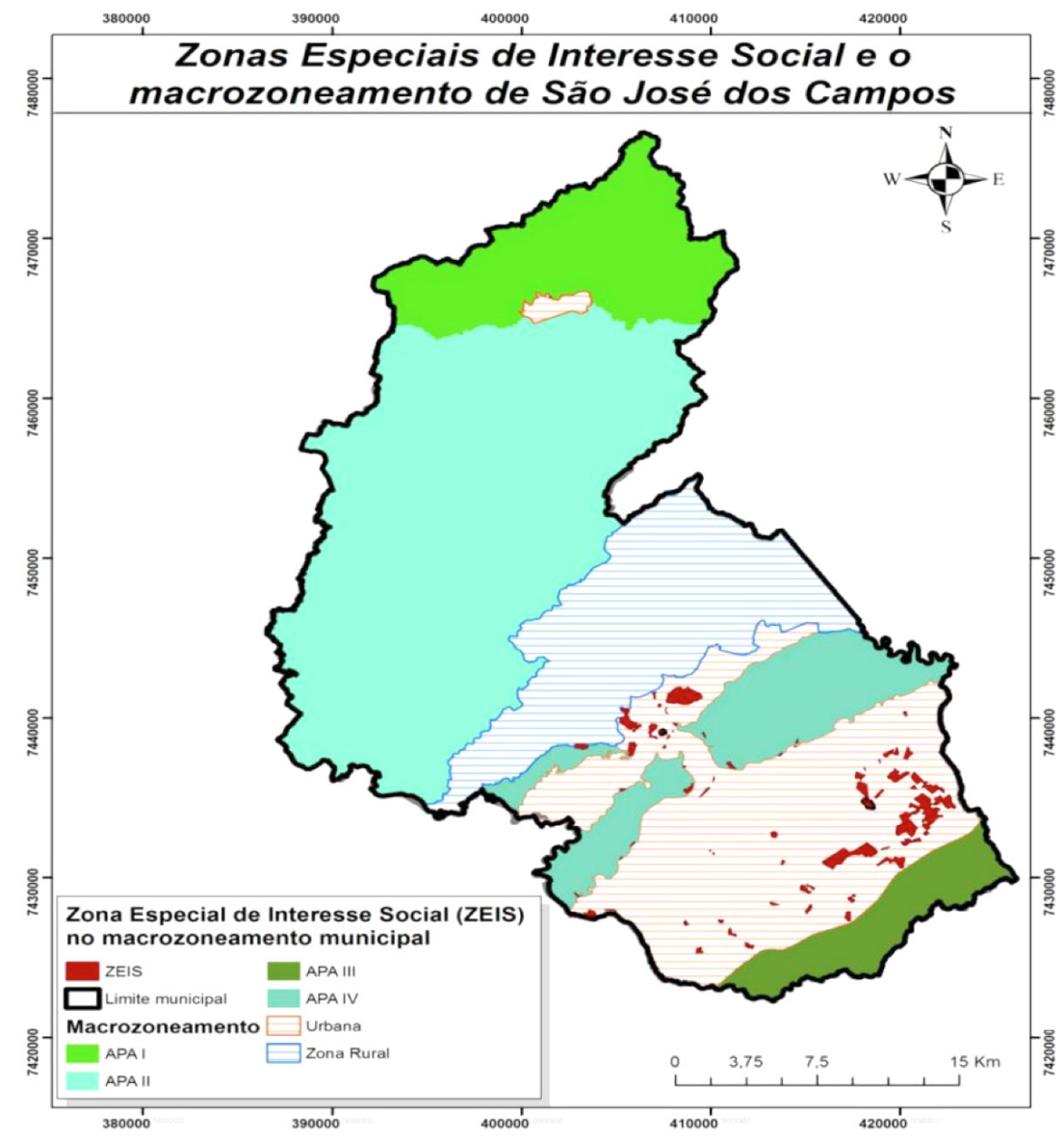


Figura 3: Classes de Declividade das ZEIS nas regiões geográficas São José dos Campos / SP. Fonte: Adaptado de: Valerio Filho et al. (2014).

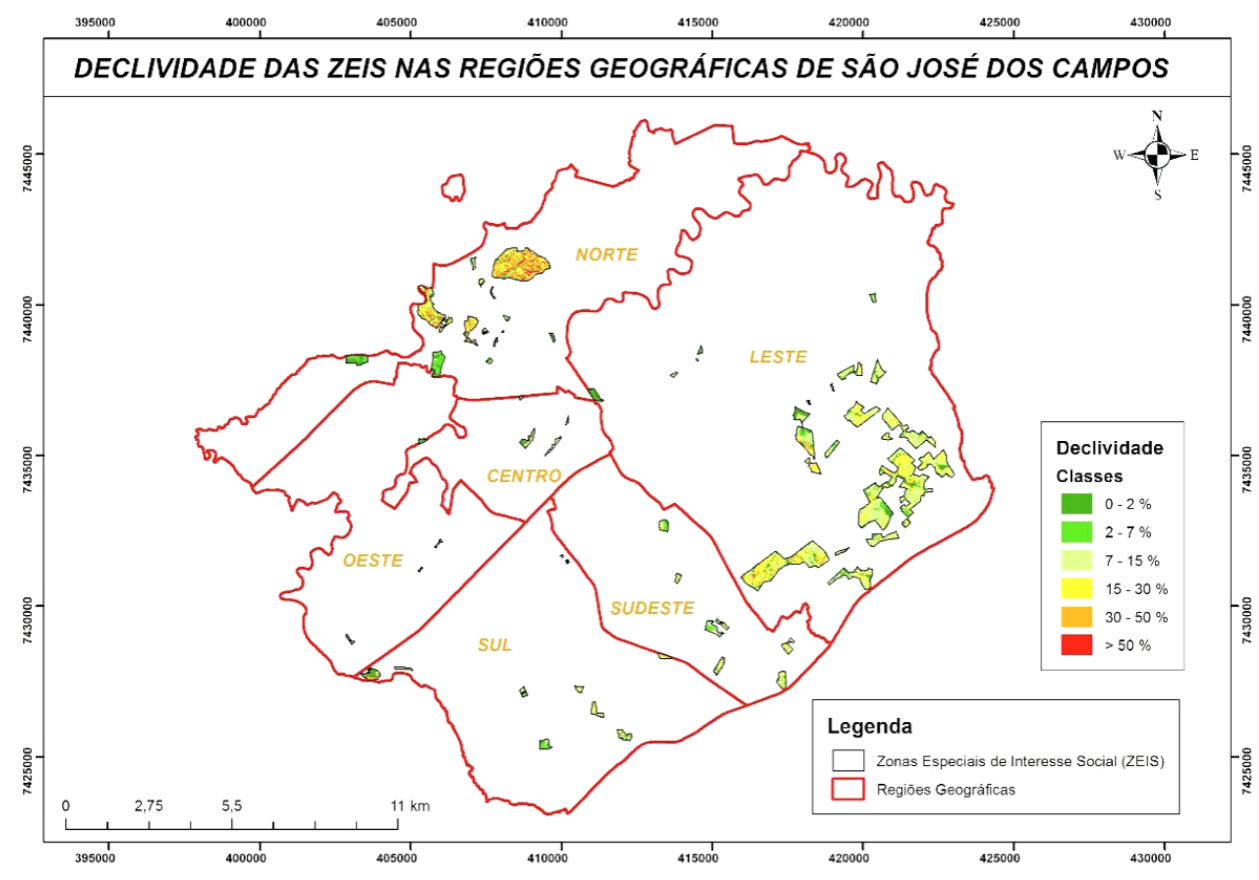

A maioria dos loteamentos irregulares delimitados como ZEIS, localizados na Zona Norte, estão em áreas de Risco, mapeados pela prefeitura desde o ano de 2005 como locais definidos como áreas de risco a deslizamentos, referendados nos mapeamentos de 2005 (IPT) e Valerio Filho et al. (2014). Os deslizamentos envolvem o maior índice de danos, tendo em vista a precariedade do local. Muitos destes casos são provenientes de ações antrópicas, falta de infraestrutura, esgoto a céu aberto, inexistência de drenagem de águas pluviais, em localizações de declividade superior a 30\%. Neste contexto, a região norte é a que apresenta maior criticidade quanto a classe de declividade, por apresentar na maior parte das ZEIS declividade acima de 30\% (Figura 3). O Censo Demográfico de (2010) registrou, que apenas quatro assentamentos da região norte tem uma população de 7.131 moradores, distribuídos em cerca de 2.005 domicílio. Já na Zona Sul, onde se destaca o bairro Rio Comprido, com 662 domicílios que concentram 2.378 moradores.

O bairro Rio Comprido (área de ZEIS) sofreu no mês de janeiro de 2011 um deslizamento de terras, em que cinco pessoas morreram soterradas no local. O bairro concentra 234 casas em áreas de risco; a justiça deu ultimato para desocupação dos imóveis. Passados quase dez anos do ocorrido o bairro continua irregular e a área considerada de risco voltou a ser ocupada, inclusive por famílias vindas de outros loteamentos irregulares da cidade de São José dos Campos.

A infraestrutura nas regiões de ZEIS, em São José dos Campos, cumpre com os atendimentos em quase sua totalidade de água, nas regiões norte, sudeste e central, apresentam-se $100 \%$ das áreas com ligações. O mesmo para a iluminação pública que atende a $100 \%$ em todas as regiões. As ligações de esgoto são as mais problemáticas, 
3 São regidas pela legislação ambiental vigente, que impõe restrições ambientais, estas áreas de preservação permanente foram instituídas pelo Código Florestal Brasileiro, através da Lei Federal 12.651/2.012

Figura 4: Porcentagem de Infraestrutura nos loteamentos irregulares em ZEIS. Fonte: Adaptado Prefeitura Municipal de São José dos Campos/ SP - 2016. pois, nas regiões norte e sudeste atendem a faixa de $60 \%$, a sudeste $50 \%$, e a região Leste onde o número de lotes é muito maior apresenta menos de $40 \%$. Esta situação concorre para um grave problema, que compromete as áreas de saúde e ambiental, pelo fato do esgoto destas áreas ainda se darem em sua maioria a céu aberto ou fossas negras, que não fazem a filtragem necessária e acabam por comprometer o lençol freático. (Figura 4).

A ausência ou precariedade dos sistemas de coleta e tratamento de esgoto, drenagem urbana e pavimentação, aumenta a possibilidade de ocorrência de deslizamentos em áreas ambientalmente frágeis. (KÖNIG, et al., (2019); MENDES, et al. (2018), MENDES, et al., (2017). O fato da maioria das áreas irregulares localizadas em ZEIS serem desprovidas de drenagem pluvial e pavimentação, repercute em situações de erosão do solo que dificulta a locomoção nas vias internas de circulação devido a formação de sulcos de erosão nestes locais. A rede de águas pluviais e a pavimentação das vias públicas quando não executadas com os critérios necessários, poderá gerar situações de aumento da umidade do solo com maior probabilidade de ocorrência de deslizamentos, assim como no caso de ausência ou precariedade dos sistemas de coleta e tratamento de esgoto, drenagem e pavimentação, aumenta a possibilidade de ocorrência de deslizamentos em áreas ambientalmente frágeis. Resulta assim, em infiltrações nos terrenos que provocam solapamentos, deslizamentos, enchentes com prejuízo a população residente.

Soma-se a esse processo a presença dos loteamentos irregulares, inseridos em Áreas de Preservação Permanente (APP) ${ }^{3}$, a Zona Norte encerra em sua maioria lotes inseridos em APP (topo de morro), principalmente na zona rural. Com o advento da lei 13.465/2017 - que dispõe sobre a regularização fundiária rural e urbana substituindo a lei 11.977/2009 - mudanças significativas ocorreram, uma vez que na ânsia de agilizar a regularização fundiária quesito da regularização fundiária urbana, como Interesse Social, Interesse Específico e áreas localizadas em APP foram subtraídos.

\section{Loteamentos Irregulares em ZEIS - Infraestrutura}

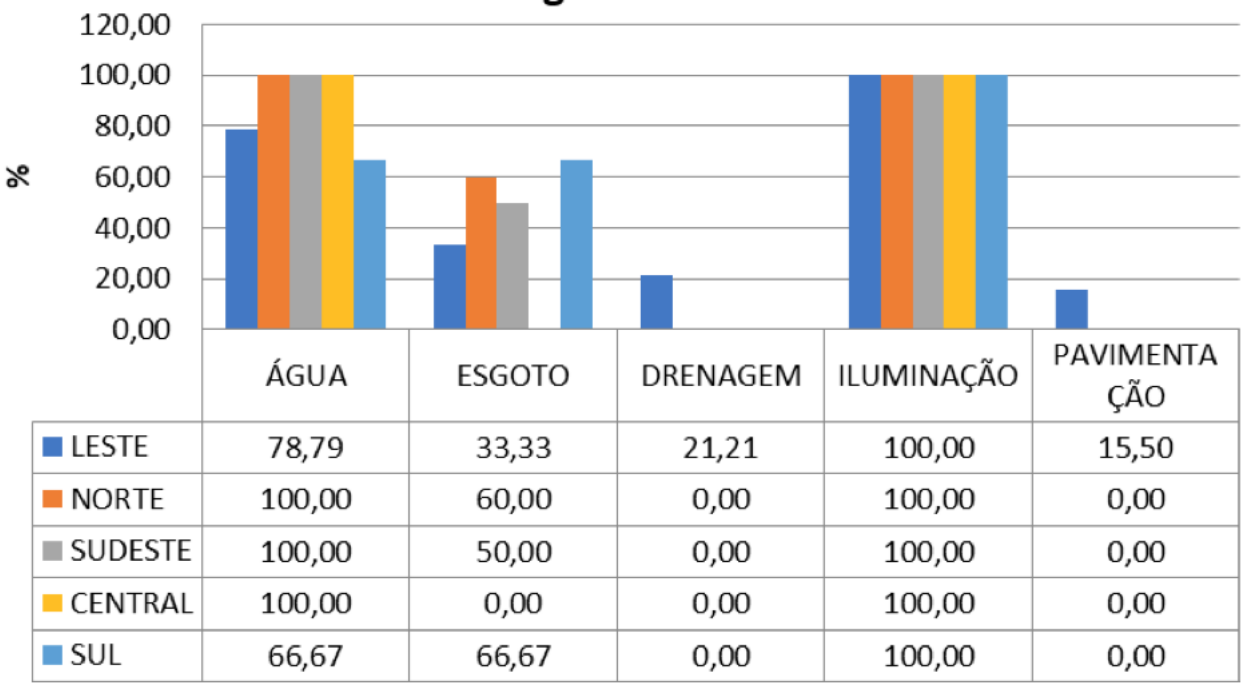


4 Altera a Lei Complementar 267/03 - Código de Obras do Município.
Até o final de 2016 a prefeitura de São José dos Campos excluía do projeto de regularização as moradias localizadas em área de risco e áreas de preservação permanente (APP), por não dispor na lei amparo legal para regularização em áreas de risco, a menos que fossem tomadas medidas mitigatórias ou corretivas no local. Deste modo, foi proibido a construção e regularização de imóveis, nestes locais.

Na busca pelo controle das construções em loteamentos irregulares, ainda no ano de 2008 foi instituído no município de São José dos Campos a Lei Complementar n. ${ }^{\circ} 373 / 08$, de 16 de setembro de $2008^{4}$ que autoriza a construção de residências unifamiliares nos loteamentos em processo de regularização fundiária classificada como ZEIS, para tanto a obrigatoriedade seria de que o loteamento irregular tivesse lei autorizativa editada pela Câmara Municipal de São José dos Campos.

O objetivo desta Lei foi de contemplar os moradores destes loteamentos que não tinham opção de moradia e para que tivessem orientação técnica na construção de casas, fossas sépticas e muros de contenção, buscando assim: a segurança da edificação e a proteção ambiental. Pretendia-se com ela minimizar a construção de moradias em áreas de proteção ambiental, áreas de risco de deslizamento de terra e melhorar as condições de segurança e salubridade das construções. Para tanto um dos quesitos de aprovação era de que o lote não poderia estar localizado em Áreas de Preservação Permanente (APP) e em áreas de risco conforme laudo emitido pela Defesa Civil. O lote também não poderia estar em área "non aedificandi" e a sua construção não poderia prejudicar os vizinhos.

A Defesa Civil do município aconselhava que caso houvesse situações de risco no loteamento a ser regularizado, proceda-se a vistoria e remoção das famílias, ao invés da tentativa de minimizar os riscos para regularização do loteamento em sua totalidade. Deste modo, os loteamentos com existência de situação de risco, a orientação é de que fossem identificados pela Defesa Civil do município e assim providenciado à remoção dos moradores do local, com o pagamento de aluguel social, assim como, a inserção em programa habitacional do município visando fornecer meios para que este obtenha sua moradia popular, minimizando as perdas da construção em áreas de risco.

Durante o processo de regularização fundiária se comprovados por Laudo da Defesa Civil a existência de áreas de risco alto ou muito alto, o loteamento não será regularizado em sua integridade, sendo regularizado apenas as áreas que não apresentassem risco e as demais apresentando ou não habitações seriam caracterizadas como áreas remanescentes. Nestes termos foram regularizados os loteamentos Altos do Caetê, Santa Helena, Chácaras Araújo I e Boa Esperança, aprovados e registrados no Cartório de Registro do Município. Na Zona Leste de São José dos Campos.

No entanto, ainda, em 2018, segundo dados da Prefeitura Municipal de São José dos Campos havia 110 loteamentos irregulares no município. O que nos levou a compor a hipótese que para parte significativa dos novos moradores de São José dos Campos, cerca de $15 \%$ da população, o acesso à terra urbana ou moradia se deu em áreas cujo valor era baixo, novos loteamentos foram criados e passaram a abrigar centenas de famílias, muitos desses loteamentos são irregulares. Segundo a Prefeitura Municipal de São José dos Campos, um loteamento irregular se caracteriza por: 
Não obter autorização (aprovação) da Prefeitura para sua implantação; Caracteriza-se pela ausência parcial ou total de infraestrutura (rede de abastecimento de água, rede de coleta, afastamento e tratamento de esgoto, sistema de drenagem das águas pluviais, iluminação pública, pavimentação asfáltica das vias); (aracteriza-se pela ausência de um projeto urbanístico adequado de quadras, ruas, lotes; Não conta com reserva de áreas públicas para equipamentos públicos e comunitários; Apresenta sistema viário e acessos precários pela existência de ruas que não obedecem aos limites de largura e declividade permitida; Os proprietários dos lotes, em sua maioria, só possuem contrato de compra e venda não registrados em Cartório de Registro de Imóveis. (PMSJC -2018, p. 77-78)

A ocupação desses loteamentos normalmente, sofre da ação de imobiliárias e seus agentes que declaram falência após a venda, como relatado por certos moradores da Zona Norte de São José dos Campos, que hoje possuem o contrato de compra e venda do terreno onde moram, mas estão impedidos de regularizá-lo.

Atesta-se que muitos moradores desses loteamentos vivenciam a falta de alternativa habitacional seja por meio do mercado imobiliário ou por meio de Políticas Públicas como do programa como o Minha Casa Minha Vida (MCMV). Assim, na ordem capitalista as ocupações ilegais são derivadas da própria dinâmica da gestão financeira e municipal (MARICATO, 2003; HARVEY, 2005). Assim, define o Instituto Brasileiro de Geografia e Estatística:

A existência está relacionada à forte especulação imobiliária e fundiária e ao decorrente espraiamento territorial do tecido urbano, à carência de infraestruturas as mais diversas, incluindo de transporte e, por fim, à periferização da população. 2. Surgem, nesse contexto, como uma resposta de uma parcela da população à necessidade de moradia, e que irá habitar espaços menos valorizados pelo setor imobiliário e fundiário dispersos pelo tecido urbano". (IBGE-2015 - grifos nossos)

Segundo a PMSJC "O PDDI-2006 entre os fatores que contribuíram para esse processo, foi a ausência de uma política habitacional para a população de baixa renda, o alto custo da terra no Município e o alto nível de exigências e de dificuldades administrativas para a aprovação de loteamentos." (PMSJC, p.77, 2018). Em São José dos Campos há evidente questão da vulnerabilidade social ainda a ser enfrentada pelos gestores municipais (ALVARENGA, RESCHILIAN, ROSEMBACK, 2018).

\section{O caso do loteamento Santa Helena}

Para ilustrar a problemática do entrelaçamento ocupação em área de risco e loteamentos irregulares, seleciona-se o caso do bairro Santa Helena localizado numa região marcada por declividades que variam de $0 \%$ a 50\%, a predominância de seu território está na faixa dos $15 \%$ a $30 \%$ de declividade, na cota topográfica 550 que segue margeando um córrego municipal. A Figura 5 ilustra a distribuição das classes de declividade que ocorrem no Loteamento Santa Helena. Esta classe de declividade oferece restrições à implantação de edificações (MASCARÓ, 2003, p. 23) e pode-se constatar que grande parte do loteamento está nesta classe e em situações de declividades maiores. 
Figura 5 (topo): Mapa de Declividade do Loteamento Santa Helena - São José dos Campos/ SP. Fonte: Adaptado de: Valerio Filho et al. (2014).

Figura 6: llustração da distribuição das edificações do Loteamento Santa Helena em imagem orbital de alta resolução, São José dos Campos-SP. Fonte: Adaptado de: Google Earth (2016).

5 Projeto aprovado - Processo: 31.749-7/2007 e registrado no C; R; matrícula n. ${ }^{\circ} 338.102-1^{\circ}$ R.I.
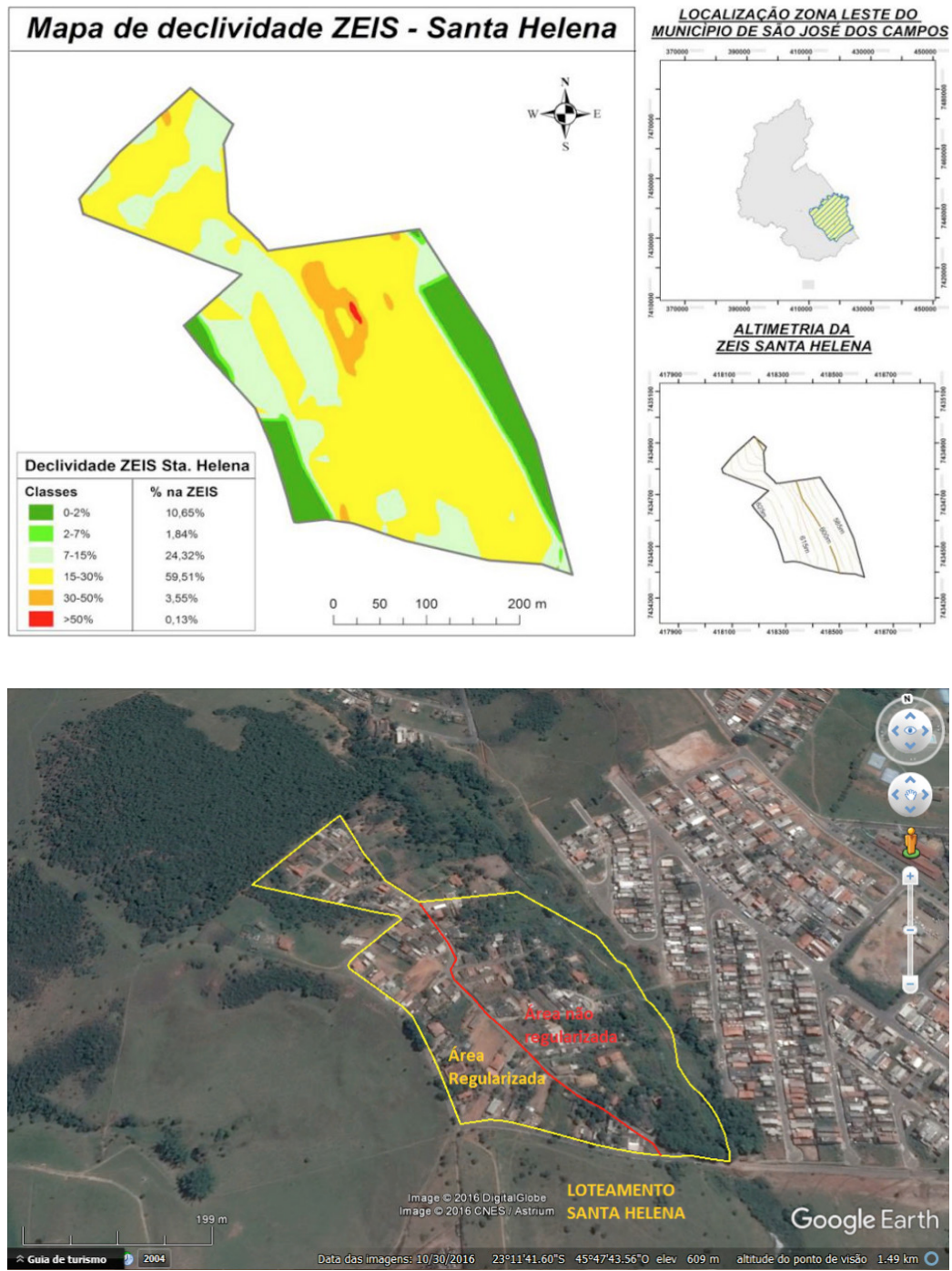

A aprovação da regularização fundiária do loteamento Santa Helena foi efetivada, através do processo 31.749/2007 e registrado sob matrícula $338.102-1 .{ }^{\circ} \mathrm{RI}$ da Comarca de São José dos Campos (Processo aprovado de acordo com as diretrizes da Lei 11.977/2009, cap. III.). A área regularizada se deu na divisória natural existente da rua, denominada Rua 02 (dois) que corta o loteamento no sentido longitudinal, porém a parte do loteamento que foi implantada na área marginal do córrego que atravessa parte do loteamento não foi regularizada, por estar inserida em área de risco a inundação. Na Figura 6, a área demarcada como área não regularizada, pode-se visualizar a ocupação no local, o crescimento do entorno e a 1.977 entender que metade do loteamento está regularizada, mas a outra metade não. Por outro lado, constata-se que o número de construções irregulares continua a crescer no lado não regularizado do loteamento. O fato mais constrangedor é que as áreas de risco continuam sendo ocupadas, as extensões de risco continuam. ${ }^{5}$ O Censo Demográfico, 2010, apontou que na região em que se inseria o bairro, havia 358 domicílios e 1.330 moradores.

Anuncia-se então que a parte regularizada tem seu direito garantido, para solicitar projeto de planta popular gratuitamente, pode financiar, vender já a outra parte do loteamento, continua o processo de construção e ocupação ilegal, pois ainda continua invisível aos olhos dos que habitam a "cidade legal". 


\section{Considerações finais}

Parte significativa dos moradores da cidade não foram inseridos dignamente ao novo modelo econômico implantado no século XX e XXI, estes expropriados das condições objetivas para ingressarem no mercado de compra e venda de imóveis ficaram à deriva da própria sorte e fizeram nos loteamentos irregulares desprovidos de qualquer infraestrutura seus espaços de moradia e vida. Áreas mais distantes dos centros urbanos, pouco atendidas por serviços básicos de saúde, educação e ambientalmente frágeis: a beira dos rios e córregos, no topo dos morros, em áreas sujeitas a deslizamentos de terra e inundações foi uma necessidade e não escolha.

Verifica-se que o crescimento dos loteamentos irregulares aumenta a situação de risco e requer que sejam tomadas medidas que favoreçam a contenção do crescimento das ocupações irregulares e proporcionem uma intervenção urbana, com ações que promovam a regularização fundiária dos loteamentos, com a finalidade de coordenar as ações irregulares e desta forma amenizar os danos causados por essas ocupações.

Contudo, mitigar risco em áreas de vulnerabilidade socioambiental ocupadas por população em sua maioria empobrecida requer um investimento em estudos de viabilização técnica para elaboração de programas efetivos, ou políticas públicas que atendam satisfatoriamente a população em vulnerabilidade-

No caso de alguns municípios como São José dos Campos, uma equipe da Defesa Civil monitora as situações de risco na cidade. No entanto, para evitar desastre ainda é necessária uma fiscalização intensiva.

No intuito de viabilizar a construção do PMRR (Plano Municipal de Redução de Riscos) o município de São José dos Campos criou em 2016 o Grupo Especial de Trabalho (GET) através da portaria n. ${ }^{\circ}$ 06/GP-DFAT/16, para coordenar e acompanhar a elaboração do PMRR, com o levantamento das áreas de risco do município e as estratégias para reduzir e erradicar os riscos de deslizamentos de encostas e inundações.

Atualmente, a lei 13. 465/17 que rege a regularização fundiária no país definiu novos instrumentos para a regularização fundiária em área urbana, rural e ambiental, que ainda estão em adaptação pelo município.

Assim, cabe ao órgão municipal disciplinar os procedimentos de regularização fundiária dentro de seus limites territoriais, buscando agir de acordo com o princípio da função social da propriedade, com soluções objetivas adequadas e simples que venham a garantir a preservação dos recursos naturais e do meio ambiente com incentivos a construção edilícia, buscando realizar a inserção social e a preservação de um meio ambiente saudável e equilibrado.

A prefeitura de São José dos Campos, no ano de 2012 criou a Secretaria de Regularização Fundiária, que atuou tão somente com o propósito de efetivar a regularização fundiária no município, na gestão atual, as secretaria de regularização fundiária se fundiu à secretaria de habitação e obras, mas dispões de equipe técnica específica para promover a regularização fundiária, desta feita vinculada a nova lei 13.465/17. 


\section{Referências bibliográficas}

ACSELRAD, Henri. Ambientalização das lutas sociais - o caso do movimento por justiça ambiental. Estudos Avançados, v.24, n.68, p.103-119, 2010.

ALVARENGA, Daniela. N.; RESCHILIAN, Paulo. Romano.; ROSEMBACK, Roberta. Guerra. Local de moradia e vulnerabilidade social na região metropolitana do Vale do Paraíba e litoral norte e em São José dos Campos - SP. Oculum ensaios. v.15, p.149 - 2018.

ALVARENGA, Daniela. N.; RESCHILIAN, Paulo. Romano. Financeirização da Moradia e Segregação Socioespacial: Minha Casa, Minha Vida em São José Dos Campos, Taubaté e Jacareí - SP. Urbe. Revista Brasileira de Gestão Urbana, v.10, p.473 - 484, 2018.

BAENINGER, Rosana; DEDECCA, Claudio; MONTALI, Lilia; LEONE, Eugênia; TELLES, Stella; BALTAR, Claudia. Polos regionais - São José dos Campos, Sorocaba e Ribeirão Preto/. Campinas: Núcleo de Estudos de População/Núcleo de Estudos de Políticas Públicas/Instituto de Economia-Unicamp, 2010.

BRASIL. Lei 11.977, de 07 de julho de 2009. Dispõe sobre o Programa Minha Casa, Minha Vida - PMCMV e a regularização fundiária de assentamentos localizados em áreas urbanas. Disponível em: <www.planalto.gov.br/ccivil_03/_ato2007-2010/2009/lei/111977.htm>.

Lei 12.424, de 16 de junho de 2011. Altera a Lei 11.977, de 7 de Julho de 2009. Disponível em: <www.planalto.gov.br/ccivil_03/_ato2011-2014/2011/lei/12424.htm>.

. Lei 12.608, de 04 de dezembro de 2012. Dispõe sobre o Sistema Nacional de Proteção e Defesa Civil -SINPDEC e o Conselho Nacional de Proteção de Defesa Civil - CONPDEC. Disponível em: <www.planalto.gov.br/ccivil_03/_ato2011-2014/2012/lei/l12608.htm>.

Lei 12.651, de 25 de maio de 2012. Dispõe sobre a proteção da vegetação nativa. Disponível em: <www.planalto.gov.br/ccivil_03/_ato2011-2014/2012/lei/12651.htm>.

Lei 13.465, de 11 de julho de 2017. Dispõe sobre a regularização fundiária rural e urbana, sobre a liquidação de créditos concedidos aos assentados da reforma agrária e sobre a regularização fundiária no âmbito da Amazônia Legal. Disponível em: <www. planalto.gov.br/ccivil_03/_Ato2015-2018/2017/Lei/L13465.htm>.

CANO, Wilson. Raízes da concentração Industrial em São Paulo. Campinas, Ed. da Unicamp. 1990.

CARTIER,Ruy; BARCELLOS,Christovam; HUBNER,Cristiane; PORTO, Marcelo Firpo. Vulnerabilidade social e risco ambiental: uma abordagem metodológica para avaliação de injustiça ambiental. Cad. Saúde Pública, Rio de Janeiro, v. 25, n. 12, p. 2695-2704, dez. 2009.

CUNHA, José Marcos Pinto da; SILVA, késia Anastácio Alves da; BECCENERI, Leandro Blaque. Vale do Paraíba e Litoral Norte. Diversidade socioespaciais. Campinas. Editora Librium. 2019.

DURHAM, Eunice. A caminho da cidade. São Paulo: Perspectiva.1973.

FERNANDES, Edésio. Regularização de assentamentos informais: o grande desafio dos municípios, da sociedade e dos juristas brasileiros Regularização fundiária sustentável - ROLNIK, Raquel. Et. Al. Conceitos e diretrizes. Brasília: Ministério das Cidades, 2007.

FERRAZ, Patricia. André. de Camargo. "Regularização Fundiária e Desenvolvimento Econômico Sustentado: Novos instrumentos para regularização de terras urbanas. Alternativas de custeio." In NALINI, José Renato e LEVY, Wilson - Regularização Fundiária - De acordo com a Lei 12.651/2012 - Novo Código Florestal com a redação dada pela lei 12.727/2012 - Rio de Janeiro - Editora Forense Ltda., 2014.

GOMES, Cilene, RESCHILIAN, Paulo Romano, UEHARA, Agnes. Perspectivas do planejamento regional do Vale do Paraíba e litoral norte: marcos históricos e a institucionalização da região metropolitana no Plano de Ação da Macrometrópole Paulista. urbe. Revista Brasileira de Gestão Urbana (Brazilian Journal of Urban Management), 2018 jan./abr., 10(1), 154-171. 
GOOGLE EARTH. Loteamento Santa Helena no Brasil. 2016.

GOUVÊA, Rosana Aparecida Ravanelli. O espaço urbano e a clandestinidade: um estudo de caso dos loteamentos clandestinos no município de São José dos Campos-SP. Dissertação (Mestrado em Planejamento Urbano e Regional) Instituto de Pesquisa e Desenvolvimento, UNIVAP. São José dos Campos-SP. 2003.

GUNN, Philip. A mídia na guerra dos lugares: A experiência tucana no Ceará. In: Deak, Csaba, Schiffer, Sueli Ramos. O processo de urbanização no Brasil. São Paulo: Editora da Universidade de São Paulo, 2010.

HARVEY, David. A produção capitalista do espaço. São Paulo: Annablume, 2005.

INSTITUTO BRASILEIRO DE GEOGRAFIA E ESTATÍ́STICA. Censo demografico 2010. Disponível em: <www.censo2010.ibge.gov.br>. Acesso em: 20 out. 2015

IPT-Instituto de Pesquisas Tecnológicas do Estado de São Paulo (2005). Mapeamento de áreas de risco de municípios do Estado de São Paulo - município de São José dos Campos (SP), Relatório Técnico no 82 914-205, 145p + anexo (Mapa).

KOWARICK, Lucio. A espoliação urbana. São Paulo, Paz e Terra. 1979.

KÖNIG, Téhrrie; KUX, Hermann; MENDES, Rodolfo Mendes. Shalstab mathematical model and WorldView-2 satellite images to identification of landslide-susceptible areas. Natural hazards (dordrecht. Online), v. 98, p. 1-23, 2019.

KURKDJIAN, Maria Lourdes Neves de Oliveira, VALERIO FILHO, Mario, NIERO, Madalena, VENEZIANI, Paulo, FLORENZANO, Teresa Gallotti (orgs). Macrozoneamento da Região do Vale do Paraíba e Litoral Norte do Estado de São Paulo. São José dos Campos: INPE, 1992, p. 215.

LEITE, Ricardo Pereira. "Regularização Fundiária - PMSP. " In. NALINI, José Renato e LEVY, Wilson. Regularização Fundiária - De acordo com a Lei 12.651/2012 - Novo Código Florestal com a redação dada pela lei 12.727/2012 - Rio de Janeiro - Editora Forense Ltda., 2014.

INSTITUTO DE PESQUISA E PLANEJAMENTO - IPPLAN. Avaliação de Áreas de Risco do Município de São José dos Campos (consulta na internet: <https://www.sjc.sp.gov.br/media/45004/ pmrr_final_i_e_ii.pdf> em 15/08/2019).

NEGRI, Barja. Concentração e Desconcentração Industrial em São Paulo (1880 - 1990). Unicamp, Ed. da Unicamp. 1996.

MARICATO, Ermínia. Metrópole, legislação e desigualdade. Estudos Avançados. 17 (48), 2003.

. Urbanismo na periferia do mundo globalizado metrópoles brasileiras. São Paulo em perspectiva, 14(4) 2000. Pp. 22-33.

MACIEL, Lidiane. O sentido de melhorar de vida: arranjos familiares na migração rural-urbana para o interior de São Paulo. Jundiaí, Paco Editorial. 2013.

MARANDOLA JR., Eduardo; HOGAN, Daniel. As dimensões da vulnerabilidade. São Paulo em perspectiva, v. 20, n. 1, p. 33-43, jan./mar., 2006.

MASCARÓ, Juan. Luis. Loteamentos urbanos. Porto Alegre: L. Mascaró, 2003.

MENDES, Rodolfo Moreda; ANDRADE, Marcio Roberto Magalhães de; TOMASELLA, Javier; SCOFIELD, Graziela. Understanding shallow landslides in Campos do Jordão municipality Brazil: disentangling the anthropic effects from natural causes in the disaster of 2000. Natural hazards and earth system sciences, v. 18, p. 15-30, 2018.

MENDES, Rodolfo Moreda; ANDRADE, Marcio Roberto Magalhães de; PRIETO, Carla. C.; ÁVILA, Frederico Fernandes de; CAMARINHA, Celso Aluísio; MIONI, Pedro Ivo. Stability Analysis on Urban Slopes: Case Study of an Anthropogenic-Induced Landslide in São José dos Campos, Brazil. Geotechnical and Geological Engineering, v. 36, p. 599-610, 2017. 
REIS, Nestor Goulart. Notas sobre urbanização dispersa e novas formas de tecido urbano. São Paulo: Via das Artes, 2006.

ROLNIK, Raquel. A Cidade e a Lei: legislação, política urbana e territórios da cidade de São Paulo. São Paulo: Studio Nobel: FAPESP, 1997.

SÃO JOSÉ DOS CAMPOS. Lei complementar 428, de 09 de agosto de 2010. Estabelece normas relativas ao parcelamento, uso e ocupação do solo São José dos Campos e dá outras providências. Disponível em: <www.sjc.sp.gov.br/media/350292/lc42810.pdf>.

Prefeitura. Banco de Dados Geográfico Cidade Viva. São José dos Campos, 2011. [CD-ROM.].

Prefeitura. Relação dos Loteamentos Aprovados (consulta na internet, <www. sjc.sp.gov.br/servicos/gestao-habitacional-e-obras/regularizacao-fundiaria/loteamentos-regularizados/>, em 15/08/2019).

Prefeitura. Relação dos Loteamentos em regularização (consulta na internet, <www. sjc.sp.gov.br/servicos/gestao-habitacional-e-obras/regularizacao-fundiaria/loteamentos-em-regularizacao/>, em 15/08/2019.

SCHIFFER, Sueli. Ramos. São Paulo como polo dominante no mercado unificado nacional. DEAK, Csaba, SCHIFFER, Sueli Ramos (organizadores). O Processo de Urbanização no Brasil. São Paulo: Editora da Universidade de São Paulo, 2010.

SEADE (Fundação Sistema Estadual de Análise de Dados). <http://catalogo.governoaberto. sp.gov.br/organization/fundacao-sistema-estadual-de-analise-de-dados-seade>.

TAVARES, Jefferson Cristiano. Planejamento Regional no Estado de São Paulo: Polos, Eixos e a Região dos Vetores Produtivos. Rev. Bras. Estud. Urbanos Reg., SÃO PAULO, V.20, N.2, p.344-367, MAIO. -AGO. 2018.

TOMINAGA, Lídia Keiko. SANTORO, Jair; AMARAL, Rosangela. do (orgs.) Desastres naturais. conhecer para prevenir. São Paulo: Instituto Geológico, 2009.

VALERIO FILHO, Mario; MENDES, Rodolfo Moreda; FARIA, Daniela Gírio Marchiori (orgs). Mapeamento das áreas de risco associados a escorregamentos de encostas no município de São Jose dos Campos - SP. Relatório Técnico Final, Convenio UNIVAP/PMSJC, Processo Nº 53.366/2013, São José dos Campos, 60p.anexos, 2014.

VILLAÇA, Flávio. Espaço Intra-Urbano no Brasil. São Paulo: Estúdio Nobel, FAPESP: Lincoln Institute, 2001

VALÊNCIO, Norma. Sociologia dos desastres - construção, interfaces e perspectivas no Brasil volume II /organizado por Norma Valencio- São Carlos: RiMa Editora, 2010. 